915

\section{INFECTIOUS MONONUCLEOSIS AND ADOLESCENTS}

M. Ilic

Health Centre Savski Venac, Belgrade, Serbia

Introduction: Epstein-Barr virus (EBV) is ubiquitous virus that causes infectious mononucleosis(IM),mostly during adolescence .Clinical presentation of IM may be varying, so it's differential diagnosis. Laboratory tests for EBV are expensive, time consuming and not always foolproof.Aimln primary pediatric care is important during first visit to separate IM from mononucleosislike diseases.

Material: Twenty patients with IM aged 8 to 23 years were investigated between December 2007. and January 2009., on the basis of clinical symptoms and blood tests.

Results: Several days before onset of IM, one third of patients had malaise and "itching in the throat". The most frequent symptoms (95\%) were low grade fever, pharyngitis and lymphadenopathy. Pharyngitis was mostly exudative, with massive tonsillar enlargement and with palatial petechiae in $35 \%$ of patients. We found the prominent lymphadenophaty of posterior lymph nodes, particularly of epitrochlear nodes $(40 \%)$. Half of the patients had moderate splenomegaly and $10 \%$ hepatomegaly. Compete blood count showed leucocytes $\left(>12 \times 10^{9} / I\right)$ with lymphocyte/leukocyte ratio averaged 0.51 and presence of atypical lymphocytes in $35 \%$ of the patients.

Conclusions: Appreciation of IM's most prominent clinical presentations and laboratory tests will enable pediatricians to treat children more effectively. The importance of quick diagnosis of IM is to provide appropriate treatment and prevention of potential complications.

\section{PREVALENCE AND CAUSES OF CHRONIC COUGH AMONG IN-PATIENT CHILDREN IN TERTIARY CARE HOSPITAL}

\author{
I. Butiene ${ }^{1}, A$. Valiulis ${ }^{2}$
}

${ }^{1}$ Department of Pathology, Pharmacology and Forensic Medicine, ${ }^{2}$ Department of Pediatrics, Vilnius University, Faculty of Medicine, Vilnius, Lithuania

Background: Chronic cough, defined as coughing for more than four weeks, is a common problem in childhood, but data about the causes are scarce.

Aim: To determine the prevalence, distribution by duration and common causes of chronic cough in children.

Methods: We retrospectively analyzed the 9315 clinical records of pediatric patients aged 1 month to 18 years, hospitalized in Department of Pediatrics of Vilnius City University Hospital in 2007-2009. Children referred to the hospital with chronic cough were divided into 3 groups according to cough duration: 4 weeks (group 1), 5-8 weeks (group 2), and more than 9 weeks (group 3)

Results: Chronic cough was found in 183 (1.964\%) children, mean age 6.32; SD 4.801 [1.0-17.0]. 71 children referred to the hospital for cough, persisting for 4 weeks, 74 - for 5-8, 37 - for more than 9 weeks. The most often diagnosed diseases were protracted bronchitis $(34.6 \%)$, bronchial asthma (26.3\%), pneumonia (23.6\%), and sinusitis (10.9\%). Chronic cough was caused by more than one disease for $75.8 \%$ of children. There where no differences between children coughing for 4, 5-8, and more than 9 weeks: protracted bronchitis was diagnosed in $38.6 \%, 40.9 \%$ and $20.5 \%$, bronchial asthma $-36.9 \%, 36.9 \%$ and $26.2 \%$, sinusitis $38,9 \%$, $38.9 \%$ and $22.1 \%$, respectively.

Conclusion: The prevalence of chronic cough in pediatric setting was $1.96 \%$. The most common causes of chronic cough were protracted bronchitis, bronchial asthma, pneumonia and sinusitis. There were no differences between cough duration and common causes of chronic cough in children. 